\title{
Superior gluteal artery perforator flap for meningomyelocele defect: A saviour when other options vanish
}

Sir,

Early repair of meningomyelocele prevents infection, eliminates cerebrospinal fluid leaks, preserves neural function and diminishes late sequelae such as pain over the repair site. Neurosurgeons can usually reconstruct both spinal and skin defects. Although primary closure is sufficient in most cases, when the defect is larger, skin flaps are required. A variety of random flaps, different suture techniques and surgical materials have been described for the reconstruction of meningomyelocele defects. ${ }^{[1,2]}$ Most of these techniques achieve successful results. But sometimes, partial or total losses of the flaps can be encountered. In these situations, as the surrounding soft tissue coverage is insufficient, the defect becomes larger and more difficult to reconstruct than the primary defect.

We reconstructed such a complex defect with the Superior Gluteal Artery Perforator (SGAP) flap after two previously failed operations and wish to discuss the advantages of SGAP flap in complicated cases.

A two-day-old girl with a meningomyelocele was operated on by the paediatric neurosurgery department. The dura was repaired with artificial biomaterial,

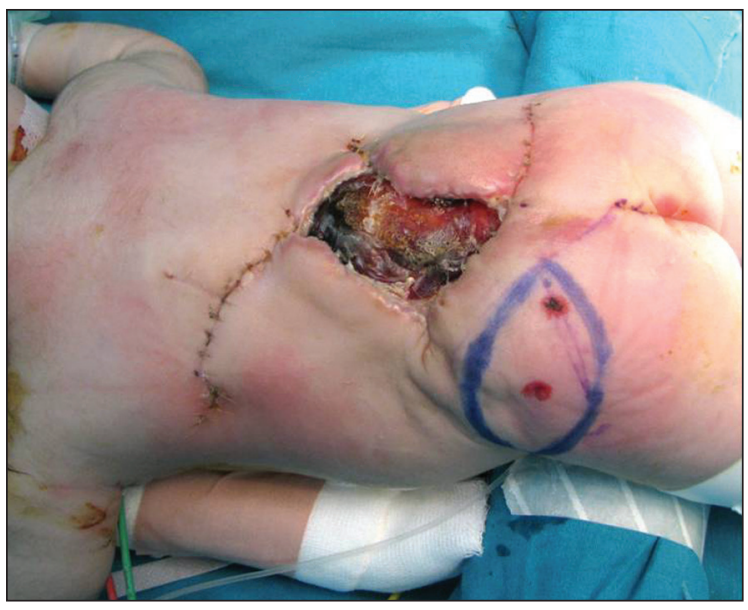

Figure 1: Dehiscence was encountered following defect closure with opposing fascia cutaneous flaps due to cerebrospinal fluid leakage and tissue oedema. Reconstruction was planned with an SGAP flap 


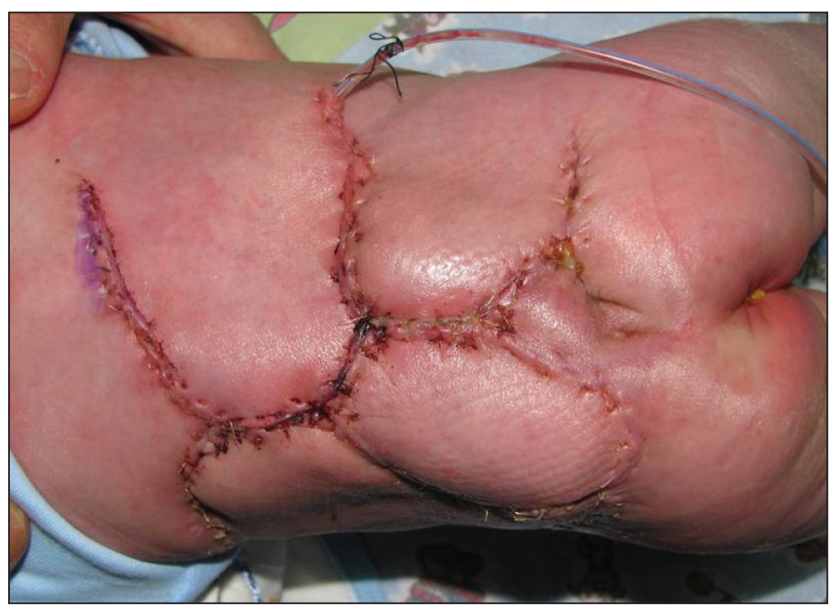

Figure 2: One week postoperatively, the patient was discharged from the hospital with no further complications. The additional scars on the superior dorsum were of the original opposing fasciocutaneous flaps of the first operations that were re-elevated and transposed to the defect area

and skin was closed by approximation with double opposing fasciocutaneous flaps. On post-operative day seven, however, there was wound dehiscence. During the second operation, continuation of cerebrospinal fluid leakage was noted and dural repair was repeated. Skin flaps were re-elevated, and skin was closed under minimal tension. On the fifth day, increased oedema caused repeat dehiscence. Due to previous operations, the surrounding tissue was unsuitable for reconstruction. Therefore, we decided to reconstruct the defect using an SGAP flap [Figure 1]. A suprafascial dissection was preferred, and a small cuff of muscle was left intact around the perforator vessels to avoid vasospasm. One week postoperatively, the patient was discharged from the hospital with no further complications [Figure 2].

The perforators arising from the SGA are approximately $1-2 \mathrm{~mm}$ in newborns, and caution should be taken not to damage the vascular pedicle during dissection. ${ }^{[3]}$ Leaving a small cuff of muscle around the pedicle can be beneficial in decreasing the risk of harming the pedicle or vasospasm. Yet, caution should be taken, as leaving a cuff of muscle around the pedicle will hide small vascular branches and lead to a more bloody dissection if they go unnoticed.

Perforator flaps have been used in reconstruction of meningomyelocele in three previous reports. ${ }^{[3-5]}$ Of these studies, Duffy et al. used the SGAP flap in six patients with large primary meningomyelocele defects. This is the second report of using the SGAP flap for reconstruction of a meningomyelocele defect. Although it's a reliable alternative in experienced hands, we believe it should be reserved for secondary reconstructions or very large primary cases where an easier alternative would result in inadequate closure. We can conclude that the SGAP flap can be a saviour in complicated meningomyelocele defects.

\section{Ismail Kucuker, Billur Sezgin'1,} Serhan Tuncer ${ }^{2}$, Suhan Ayhan ${ }^{2}$

Department of Plastic, Reconstructive and Aesthetic Surgery, Ondokuz Mayis University Hospital, Samsun, ${ }^{1}$ Erzurum Regional Training and Research Hospital, Erzurum, ${ }^{2}$ Gazi University Hospital, Ankara, Turkey

Address for correspondence: Dr. Billur Sezgin, Department of Plastic, Reconstructive and Aesthetic Surgery, Erzurum Regional Training and Research Hospital, $1^{\text {st }}$ Floor Clinics, Cat Yolu - 25070, Erzurum, Turkey.

E-mail: billursezgin@hotmail.com

\section{REFERENCES}

1. Komuro $\mathrm{Y}$, Yanai A, Koga $\mathrm{Y}$, Seno H, Inoue M. Bilateral modified $\mathrm{V}-\mathrm{Y}$ advancement flaps for closing meningomyelocele defects. Ann PlastSurg 2006;57:195-8.

2. Ozçelik D, Yildiz KH, Iş M, Döşoğlu M. Soft tissue closure and plastic surgical aspects of large dorsal myelomeningocele defects (review of techniques). Neurosurg Rev 2005;28:218-25.

3. Duffy FJ Jr, Weprin BE, Swift DM. A new approach to closure of large lumbosacral myelomeningoceles: The superior gluteal artery perforator flap. Plast Reconstr Surg 2004;114:1864-70.

4. Van Landuyt K, Hamdi M, Blondeel P, Tonnard P, Verpaele A, Monstrey S. Free perforator flaps in children. Plast Reconstr Surg 2005;116:159-69.

5. Muneuchi G, Matsumoto $\mathrm{Y}$, Tamai M, Kogure $\mathrm{T}$, Igawa $\mathrm{HH}$, Nagao S. Rhomboid perforator flap for a large skin defect due to lumbosacral meningocele: A simple and reliable modification. Ann Plast Surg 2005;54:670-2.

\begin{tabular}{|l|l|}
\hline \multicolumn{2}{|c|}{ Access this article online } \\
\hline Quick Response Code: & Website: \\
\hline & www.ijps.org \\
\cline { 2 - 2 } & \\
\hline
\end{tabular}

